\title{
DŽ. R. R. TOLKIN, FANTASTIKA I REALIZAM: „O BAJKAMA” I GOSPODAR PRSTENOVA*
}

U radu se razmatra čuvena trilogija Dž. R. R. Tolkina, Gospodar prstenova, najpre u kontekstu Tolkinovog predavanja „O bajkama”. Cilj rada jeste da se ukaže na problematičnu prirodu Tolkinove fantastike i realizma koju, smatramo, upravo ova trilogija najbolje ilustruje. Naime, uprkos tome što Tolkin u predavanju naglašava „oporavak, (veliko) bekstvo i utehu” koje fantastika omogućava čitaocu, u Gospodaru prstenova upadljivo je to da autor prilikom stvaranja svog fantastičnog sveta poseže za vrlo specifičnim naučnim disciplinama, verno reprodukujući njihove metodologije. Ovakav narativno-ideološki izbor nužno problematizuje odnos fantastike i realizma, kao i imaginacije i stvarnosti, jer rezultira mimetičnom istorijom koja je tek minimalno izmeštena u odnosu na političke i vojne igre moći iz stvarnog sveta.

Ključne reči: fantastika, ideologija, moć, nauka, realizam.

\section{UvOD: „O BAJKAMA”}

Tolkinova (J. R. R. Tolkien) „priča” na preko hiljadu strana ${ }^{1}$ pred- $^{-}$ stavlja dobar primer uzajamnih ograničenja i razotkrivanja fiktivne

Pripremljeno u okviru projekta Savremeni pravci u istraživanjima anglističke lingvistike $i$ anglofone književnosti $i$ kulture, koji se izvodi na Filozofskom fakultetu Univerziteta u Nišu (br. 183/1-16-1-01).

1 Preciznije, srpsko izdanje (Stylos 2012), u prevodu Zorana Stanojevića, sa predgovorom i dodacima (u sitnijem fontu) ima 1187 strana. Sada je dobar trenutak da se objasni specifično navođenje referenci i skraćenice u radu: DP, DK i PK će se odnositi na to srpsko izdanje, koje je štampano iste godine u tri odvojene knjige, 
prirode fantastike i realizma, a može da se posmatra kao pokušaj primene onih stavova koje je Tolkin izneo u svom predavanju „O bajkama” ('On Fairy-Stories')2 1939., kada je već bio započeo rad na Gospodaru prstenova. ${ }^{3}$ Pošto su Tolkinove teze iz ovog predavanja značajne ne samo za teorijsko određenje fantastike (u literaturi mnogocitirana „želja za velikim bekstvom”), i za interpretaciju Gospodara prstenova (primer podkreacije), nego i za konstruisanje implicitnog čitaoca, autora i odraslosti (igra moći u koju je duboko upletena „realističnost”), treba se prvo bliže upoznati sa njima.

Predavanje koje je Tolkin održao na univerzitetu Sveti Endruz nosi naziv „O bajkama”, ali Tolkin već u uvodu objašnjava da će govoriti o fantastičnoj književnosti uopšte: „bajke, u svakodnevnom engleskom jeziku, nisu priče o vilama i vilenjacima, nego priče o Vilinskom, odnosno, o carstvu ili stanju u kome vile postoje". Ovako definisana fantastika, prema Tolkinu, mora da se odlikuje realističnošću, koja je dužnost autora kao „pod-tvorca”; cilj je da implicitni (odrasli) čitalac bude zaveden nepobitnom realističnošću priče te da u istoj pronađe, redom, oporavak, bekstvo i utehu. U skladu sa velikim zahtevima koje postavlja pred fantastiku, Tolkin, dalje, smatra da je od suštinske važnosti da bilo koja fantastična priča bude predstavljena kao „istinita”. Upravo zato što se bavi „čudima”, navodi Tolkin, nedopustivo je da postoji nekakav okvir ili mašinerija koja će sugerisati da je ta priča u

kao Družina Prstena, Dve kule i Povratak kralja. Takođe se u pojedinim delovima javljaju reference označene sa Tolkien 1995 i brojem stranice - reč je o engleskom izdanju koje je štampano kao jedna knjiga, sa izuzetno važnim indeksom koga uopšte nema u srpskoj verziji iz 2012; prevod je autorkin.

2 http://brainstorm-services.com/wcu-2004/fairystories-tolkien.pdf, pristupljeno 20. septembra 2017. Prevod sa engleskog autorkin. Pošto je reč o dokumentu sa interneta, nisu navodene stranice.

3 Gospodar prstenova je objavljen u periodu od 1954. do 1955., ali je pisan trinaest godina, od 1936. do 1949, na zahtev Tolkinovih izdavača koji su tražili nastavak Hobita (Hobit je objavljen 193\%., a Tolkin ga je, takođe, pisao nekoliko godina). V. Christina Scull, "What did he know and when did he know it?" za detaljnu hronologiju o Tolkinovom planiranju i pisanju trilogije (u The Lord of the Rings, 1954-2004 : Scholarship in Honor of Richard E. Blackwelder, edited by Wayne G. Hammond, Christina Scull. 2006 Marquette University Press: 101-113). 
kojoj se čuda dešavaju proizvod mašte ili iluzija - za razliku od Cvetana Todorova (ToDorov 1975), za Tolkina je željena čitaočeva reakcija prihvatanje, a ne oklevanje pred prirodom predstavljenog fantastičnog sveta. Međutim, navodnici koje Tolkin koristi uz reči „istinita” i „čuda” dalje kvalifikuju prirodu tog prihvatanja i, samim tim, funkciju fantastike. Tolkin, naime, ne poziva na slepu veru u natprirodno ili čudesno, naprotiv: „kada ljudi ne bi mogli da razlikuju žabe od muškaraca, nikada ne bismo imali bajke o začaranim prinčevima-žapcima”. I mada se Kolridževo (S.T. Coleridge) „,oljno ukidanje neverice na trenutak" nameće kao precizan opis onoga što se prema Tolkinu dešava prilikom čitanja fantastike, on to eksplicitno odbacuje:

To stanje uma (tj. književno verovanje) se nazivalo 'voljno ukidanje neverice'. Ali, meni se čini da to nije dobar opis onoga što se dešava. Ono što se dešava jeste da se pripovedač pokazuje kao uspešan 'pod-tvorac'. On stvara drugostepeni svet u koji vaš um može da uđe. Unutar ovog sveta, ono o čemu pripoveda je 'istinito': u skladu sa zakonima tog sveta. Zato verujete, dok ste tamo. Onog trenutka kad se rodi sumnja, čarolija je prekinuta: magija, ili umetnost, su omanuli.

Tolkin, dakle, pomera naglasak sa voljnog izbora čitaoca na spisateljsku veštinu autora (koju naziva „vilinski zanat”); zadatak autora fantastike jeste stvaranje uverljivih, koherentnih, zakonima uređenih svetova u koje čitalac mora da poveruje - voljno ukidanje neverice je samo zamena za pravu stvar, ,izgovor kojim se služimo kad pristajemo na igre pretvaranja”. Budući konzervativan po političkom i religioznom opredeljenju, Tolkin, poput svog prijatelja K. S. Luisa (C. S. Lewis), i ovakvim određenjem fantastike insistira na autoritetu autora, i na poštovanju zakona. Implicitan pogled na čitaoca je takođe zanimljiv - naime, on će neizbežno poverovati da se nalazi u pod-svetu ukoliko je taj pod-svet koherentan, sa specifičnom kartografijom, istorijom, mitologijom, folklorom, lingvističkom raznovrsnošću, zakonima, rasama, klasama, kraljevima i, naravno, ratovima - drugim rečima, ukoliko je proizveden na isti način kao i dogovorna stvarnost. Druga implikacija, takođe važna, jeste da je čitalac ne samo muškarac nego i odrasla osoba, što u Tolkinovom određenju podrazumeva da je sposoban da 
napravi razliku između žaba i ljudi, i da vrednuje mape i, naročito, kraljeve.

Što se tiče teorijskog određenja bajki ili praćenja njihovih istorijskih transformacija, profesor Tolkin za to nije zainteresovan - otuda ona opravdana kritika Džeka Zajpsa (ZIPEs 2002: 150). Ono što Tolkin, međutim, posebno naglašava, baš kao i Zajps, jeste srećan završetak. Ukazujući na irelevantnost (prema njegovom mišljenju) istorijskih transformacija bajki, Tolkin navodi primer Crvenkape: „nije mnogo važno to što prepričane verzije ove priče, u kojima drvoseče spašavaju devojčicu, direktno potiču iz Peroove, u kojoj devojčicu proždere vuk. Ono štoje zaista važno jeste da se kasnije verzije srećno završavaju” (kurziv D.P.). Prema Tolkinu, dalje, odrasli čitaoci žele srećne završetke koje fantastika svakako nudi lakše nego tzv. realnost. Ipak, vredi primetiti i to da je srećni završetak koji Tolkin bira da naglasi potpuno konvencionalan i bezbedan po društveno-politički status quo: dete preživi, zločinac je kažnjen, drugost (u obliku vuka) eliminisana - sve ono što pokazuje i rasplet Gospodara prstenova. (Drugačije verzije, one u kojima bi Crvenkapa možda želela vuka, ili bila strašnija nego vuk, Tolkinu ne padaju na pamet, za razliku od, recimo, Anđele Karter (Angela Carter) ili Džona Konolija (John Connolly).

Tolkinov najznačajniji doprinos velikoj i dugoj debati oko definisanja fantastike jeste upravo to prepoznavanje da je u njenom srcu želja: „makar deo magije kojom ove priče rukuju na sreću ili nesreću čoveka jeste moć da iskoriste želje njegovog tela i njegovog srca”. I mada su „Želje njegovog tela i njegovog srca” dovoljno široka formulacija da pokrije sve od eskapstičke pastoralne književnosti pa do pornografije - koje Ketrin Hjum (Hume 1984) nimalo slučajno ubraja u fantastiku - Tolkin te želje u nastavku predavanja precizira u skladu sa svojim konzervatizmom, optimizmom i religioznim opredeljenjem.

Magija Vilinskog nije cilj sam po sebi, njena je vrednost u delovanju: među ovima je zadovoljenje određenih iskonskih ljudskih želja. Jedna od njih je da se istraže dubine prostora i vremena. Druga je da se komunicira sa drugim živim bićima. 
Još jedna iskonska ljudska želja jeste želja za „živom, ostvarenom podkreativnom umetnošću", a ispunjenje ovih (i samo ovih) želja u bajkama/fantastici rezultira oporavkom, bekstvom i utehom čitalaca.

Tolkinovo određenje ovih koncepata, kojim se takođe vredi pozabaviti, je uvek jasno vezano za stvarnost. Oporavak, na primer, podrazumeva ponovno zadobijanje jasne vizije i perspektive. Iako smatra da „,oljno ukidanje neverice” nije adekvatan opis onoga što se dešava prilikom čitanja vrhunski realizovane fantastične književnosti, i iako kasnije u predavanju iznosi zamerke na čuvenu razliku između „uobrazilje” ('fancy') i „imaginacije” ('imagination'), upravo je u Tolkinovom opisu oporavka moguće primetiti značajno naslanjanje na Kolridža. „Oporavak (koji uključuje povratak i obnavljanje zdravlja) jeste ponovno sticanje - ponovno sticanje jasne vizije. [...] U svakom slučaju treba da očistimo naše prozore, tako da stvari koje jasno vidimo budu oslobođene sive mutnoće banalnosti i poznatosti - posesivnosti”.

Ali kreativna fantastika nije samo pronalaženje „novih uglova sagledavanja stvarnosti”, ona nudi i mogućnost bekstva od iste. Kako Tolkin navodi u često citiranom paragrafu,

Zašto bismo prezirali čoveka koji, našavši se u zatvoru, pokuša da iz njega izađe i vrati se kući? Ako, kad već ne može da pobegne, razmišlja i priča o drugim temama, a ne o čuvarima i zatvorskim zidovima? Svet izvan zatvora nije postao manje stvaran ako zatvorenik ne može da ga vidi.

Eskapizam je, dalje, usko povezan sa utehom, a ova opet sa, kako Tolkin precizira, najstarijom i najdubljom ljudskom željom - željom za velikim bekstvom tj. bekstvom od smrti (kao i gladi, žeđi, bede, bola, tuge, nepravde). Ali uteha bajki, dodaje Tolkin, jeste i uteha srećnog završetka a ne samo bekstva. Za razliku od drame čija je najviša funkcija tragedija, najvažnija funkcija bajke jeste srećan kraj ili eukatastrofa, „iznenadni radosni preokret” koji, važno je naglasiti, ne poriče postojanje tuge i poraza. Eukatastrofa onda postaje evangelium - jevandelje, dobra vest: ne zato što negira tugu i poraz nego zato što prkosi onom univerzalnom konačnom porazu nudeći neuhvatljiv bljesak radosti, „radosti van zidova ovog sveta, koja potresa kao žalost”. Hrišćanski termin nije upotrebljen slučajno; nekoliko stranica kasnije Tolkin 
eksplicitno navodi da jevanđelja sadrže bajku, te da je rođenje Hrista euaktatastrofa ljudske istorije. Njegova je nada, na kraju, duboko subverzivna u svojoj jednostavnosti: „sve priče mogu da se obistine”.

Jedno čitanje Gospodara prstenova u kontekstu predavanja „O bajkama” bi bilo to da trilogija ilustruje sve razmotrene teze. Srednji svet, sa svojom geografijom, detaljnom istorijom i folklorom, rasama i jezicima, jeste upečatljiv primer podkreacije tj. „drugostepenog sveta”, dok uništenje Prstena i poraz sila zla upravo u trenutku kad sve deluje beznadežno predstavljaju eukatastrofu, koja ipak ne negira tugu niti neophodnost stalne borbe protiv sila mraka.

Malo drugačije čitanje - takođe u kontekstu predavanja „O bajkama” - ukazuje, međutim, da oni veliki zahtevi koje Tolkin postavlja pred fantastiku već u predavanju potvrđuju validnost realizma i realističnosti, dok se u samoj trilogiji otkrivaju i konkretna ograničenja, kao i fiktivna priroda istih. Subverzivna nada da sve priče mogu da se obistine, dalje, koristi da se promoviše monarhizam, hrišćanstvo, i patrijarhat, koji, naročito u Tolkinovoj interpretaciji, teško mogu da uliju nadu. Takođe, duboko ljudska želja za velikim bekstvom koja je, prema Tolkinu, u korenu fantastike, u trilogiji je stavljena u službu promovisanja upravo rata i smrti. Nazad, i sam jezik kojim se narator služi a koji povremeno neupitno podseća na „impozantnu uzvišenost Biblije kralja Džejmsa" (Mathews 2002: 82) ukazuje na to da je reč o svesnoj imitaciji ovog vrhunskog narativnog modela koji promoviše pokornost, i koji je u dugim vekovima ljudske istorije korišćen kao disciplinsko sredstvo da obezbedi poslušnost masa. Možda je u pitanju izraz vere i najdubljeg poštovanja, ali teško je ne primetiti da Tolkin, poput K. S. Luisa u serijalu Letopisi Narnije (The Chronicles of Narnia) i te kako preuzima ulogu Tvorca, mada se ograđuje terminom „podkreator".

Što se realističnosti Tolkinovog drugostepenog sveta tiče, važno je primetiti da već u predavanju „O bajkama” one dve naizgled suprotstavljene funkcije fantastike - ponovno sticanje jasnog pogleda na stvarnost, kao i bežanje od iste - ne samo što ne negiraju stvarnost, nego je postavljaju kao krajnju referentnu tačku. Ova stvarnost je, upadljivo, obeležena smrću, tugom, nepravdom, bolom, glađu, za- 
tvorima i čuvarima (što nipošto ne sporim). Još upadljivije, međutim, jeste to da profesor Tolkin insistira na moralno opravdanom mentalnom i emotivnom bežanju, a ne na borbi protiv ovih teških stvari - mada i te kako promoviše bitke i rat. I mada je teško očekivati od konzervativca kakav je oksfordski profesor filologije da se zalaže za rodnu jednakost, besklasno društvo ili socijalnu pravdu (osim ako nije u pitanju povratak kralja, što je za Tolkina, čini se, više nego dovoljna pravednost) - uočljivo je da se, uprkos onolikom vrednovanju bezgraničnih moći fantastike ta fantastika, baš kao i u Letopisima Narnije, baš kao i u Igri prestola (Game of Thrones) pokazuje kao modus u kome je nemoguće zamisliti društveno uređenje koje ne bi bilo monarhija. Gospodar prstenova, između ostalog, vrlo ubedljivo demonstrira da je njegovom autoru bilo lakše da osmisli Rivendal ili Lotlorijen nego da zamisli republiku ili društvo bez slugu. ${ }^{4}$ Što, naravno, ima posebnu težinu kada je reč o ovako uticajnoj priči. A videćemo u narednom odeljku da ni Rivendal nije nužno dokaz inventivnosti i bezgraničnosti ljudske/autorove mašte - naprotiv.

\section{KRALJEV PISAC: ISTORIJA I GEOGRAFIJA MOĆI}

Dobro je poznato da je Tolkin najpre osmislio različite jezike, ${ }^{5}$ a tek onda počeo da piše Gospodara prstenova da bi im dao kontekst: u predgovoru drugom izdanju, i sam na to ukazuje: „ovaj rad je po nadahnuću bio prvenstveno lingvistički, i započet da bi se pribavila nepohodna 'istorijska' pozadina za vilovnjačke jezike” (Tolkin 2012: 9). Ali mnogo je preciznije reći da Srednji svet ne postoji osim u obliku

4 A u uvodu studije pod nazivom Marksizam i fantastika (Marxism and Fantasy) Čajna Mjevil (China Miéville) ukazuje upravo na utopijske-revolucionarne aspekte fantastike. Najjednostavnije, „koliko god da je fantastika komodifikovana i odomaćena, potrebna nam je da promišljamo svet, i da ga promenimo" (Sadner ed. 2004: 341, kurziv D.P.).

5 Stvaranjem „vilovnjačkih jezika” Tolkin se bavio još od 1910, i nastavio sve do svoje smrti 1973. (Prema: David Salo, A Gateway to Sindarin: A Grammar of an Elvish Language from J. R. R. Tolkiens's Lord of the Rings, The University of Utah Press, 2004:, xiii) 
mapa, anala kraljevskih porodica, i istorija. Najzad, kako Tolkin navodi u predgovoru, Gospodar prstenova je „istorija Rata za Prsten” - otuda, delom, i svi oni problemi koji se javljaju kada književni kritičari pokušaju da ga klasifikuju kao roman, romansu, ep, dugačku bajku. Treba verovati Tolkinu da poznaje sopstvenu formu: u pitanju jeste fantastična istorija manje-više fantastičnih bića, ali istorija koja tematski i formalno imitira tradicionalne evropske istorije (u centru pažnje su kraljevi, bitke, sukobi oko moći), smeštena u prostor kreiran upadljivo detaljnom geografijom, antropologijom, sociologijom, filologijom - takođe evropskim (belim, kapitalističko-imperijalističkim) naučnim disciplinama. Istorija koja je, važno je već sada naglasiti, očekivano pristrasna u pogledu neskriveno britanskih hobita i anglo-saksonskih, arijevskih ljudi i vilovnjaka (otuda ono „manje-više fantastičnih bića”). To što Tolkin piše istoriju, a ne romansu ili bajku je, dalje, značajno u najmanje dva pogleda: sa jedne strane, Tolkin duboko problematizuje već težak odnos fantastike i realizma - u smislu da prilikom stvaranja fantastičnog sveta reprodukuje naučno-realistično kreiranje stvarnosti otkrivajući pri tom fiktivnu i ideološku prirodu istih. Sa druge strane, profesor Tolkin piše istoriju oslanjajući se na metodologiju gorespomenutih nauka koje su obavezni deo obaveznog obrazovanja - dakle ideološki obojen udžbenik. Možda je taj udžbenik zavodljiviji nego oni tradicionalni - najzad, ima vilovnjake i patuljke, što je pojedinim čitaocima važno - ali jeste udžbenik, i samim tim instrument moći u najširem smislu kreiranja znanja i podučavanja. (Moć znanja je u trilogiji posebno tematizovana i realizovana i kroz likove učenih, od Gandalfa do Aragorna.) U vezi sa tim, komentar Toma Šipija (Tom Shippey) posebno otkriva. Naime, činjenicu da je Tolkin za vreme svoje duge akademske karijere objavio svega nekoliko naučnih radova, i nijedan udžbenik iz filologije, predmeta koji je predavao punih trideset i pet godina, Šipi objašnjava na sledeći način: „Tolkin nikada nije prestajao da razmišlja o svom poslu niti da se bavi problemima vezanim za njega. Mislim da je, prosto, jedan od načina na koji ih je rešavao bio da ih prebaci u svoju fikciju" (SHIPPEY 2007: 269). 
Tolkinova fikcija, međutim, ne razmatra samo njegove filološke probleme, već vrlo uspešno reprodukuje metodologiju i diskurs određenih naučnih disciplina koje kreiraju dogovornu stvarnost; već ovo je, paradoksalno, u dubokom skladu i neskladu sa stavovima iznetim u predavanju „O bajkama”. Naime, realistični okvir, koji je prema Tolkinu neophodan za priču o „čudima”, toliko je nadmoćno realističan da je vrlo nelagodno razmišljati o onom drugom delu, evangeliumu koji fantastika navodno omogućava. Naučna fabrikacija Srednje zemlje, čini se, ukazuje na Tolkinov nedostatak vere upravo u ljudsku imaginaciju, ali i na njegovu „volju za moć”, onu koju toliko kažnjava kod (nekih) svojih likova.

Pri tom se, još jednom, ne radi o bilo kojoj dogovornoj stvarnosti. Mape, klasifikacija rasa i jezika (dalja uređenja jezika gramatikom, fonetikom, etimologijom itd.); istorije ali i pesme/priče o opravdanim sukobima; kao i teza da društvena stabilnost i pravednost zavise od povratka (rasno superiornog) kralja, ukazuju na antropološke, etnološke, filološke discipline koje su direktno hranile britanski imperijalistički projekat. Dovoljno je samo pogledati prolog, beleške, i dodatke koji uokviruju „istoriju Rata za Prsten” (ToLKIn 2012: 9). Prolog, na primer, svojom strukturom i tematskim preokupacijama nagoveštava narednih hiljadu i nešto stranica, i ubedljivo ukazuje na to da je sve oko Gospodara prstenova pitanje moći - ne samo moderne tehnologije (atomske bombe) koju pojedini kritičari misle da Prsten simbolizuje, nego upravo fukoovske moći proizvođenja znanja onim naučnim disciplinama koje stvaraju i disciplinuju subjekte, a kojima se profesor Tolkin služi da stvori svoj drugostepeni svet, kao i da disciplinuje i poduči svoje čitaoce (likovi su podučavani na malo drugačiji način).

Prolog je, najpre, podeljen u četiri dela, i praćen dodatnom „Beleškom o zapisima okruga”. Delovi nose nazive, redom, „O Hobitima”, „O travi-za-lulu”, „O uređenju okruga” i „O nalaženju Prstena”. Već na drugoj strani prologa nalazi se detaljna mapa Okruga, i daju se prve, najstarije i stoga, iz objektivno-naučne perspektive koja je implicitno a neupitno norma, najmanje pouzdane informacije o naseljavanju ovog geografskog prostora, što sam narator naglašava: 
Hobiti su u dalekoj prošlosti krenuli ka Zapadu. Njihove najranije priče kao da daju da se nazre jedno vreme u kome su naseljavali gornje doline Anduina, između krova Velike Zelenšume i Maglenih planina. Zašto su kasnije preduzeli težak i opasan prelazak preko planina ka Erjadoru, to više nije sigurno. Njihova predanja govore o umnožavanju Ljudi u toj zemlji, i o nekoj senci koja je pala na prašumu i zamračila je, a njeno novo ime je bilo Mrka šuma. (ToLKIN 2012: 16)

Kada je reč o samim Hobitima, oni su jasno rasijalizovani, klasifikovani u podvrste i tretirani na prepoznatljiv način imperijalističkih antropologa, sa posebnim vrednovanjem „krvi” tj. genetike:

Pre prelaska preko planina Hobiti su se već podelili u tri ponešto različita soja: Harfute, Sture, i Folohajde. Harfuti su bili tamnije kože, a sitniji i niži, i bili su bezbradi i bosi; njihove šake i stopala behu spretni i hitri; oni su se opredelili za visije i planinske kose. Sturi behu širi, krupnije građe; njihova stopala i šake veći, i više su voleli ravnice i rečne obale. Folohajdi su bili svetlije kože i kose, i bili su viši i vitkiji od drugih; oni behu poklonici drveća i šumovitih krajeva (16).

I, kasnije, ,za njih se [Hobite Istočne četvrti] dobro znalo da su Sturi velikim delom krvi, kao što su stvarno pokazivale i malje koji su mnogi gajili na podbratku. Nijedan Harfut ili Folohajd nije imao ni traga od brade" (19). Nakon geografskih podataka i antropološke klasifikacije „sojeva”, njihovih fizičkih odlika i habitata, ${ }^{6}$ narator prelazi na podatke o njihovom početku pismenosti te nudi podatke o jeziku (vestron, koji je lingua franca Srednjeg sveta). Nepouzdano ispredanje priča o prošlosti sada ustupa mesto nauci - istoriji koja barata brižljivo odabranim datumima, lokacijama i događajima. Narator-istoričar dosta vremena posvećuje objašnjenju kada je i kako počelo Okružno računanje vremena, ali i pozicioniranju istog u odnosu na računanje vremena pravih autoriteta, Vilovnjaka i Dundaina tj. kraljeva Ljudi:" „godine Trećeg razdoblja po računanju Vilovnjaka i Dundaina mogu se naći

6 Vredi, takođe, primetiti i da su fantastični Hobiti tamnije boje kože „stiniji, niži, bezbradi i bosi”, dakle poput dece, što u potpunosti odgovara stvarnoj infantilizaciji kolonizovanih naroda koji su takođe tamnije kože.

7 Kao što su i tri „soja” Hobita dalje klasifikovani prema svom odnosu sa Patuljcima (Harfuti), Ljudima (Sturi) i Vilovnjacima (Folohajdi). 
dodavanjem 1600 na datume po Okružnom računanju" (17). Događaj koji je obeležio početak Okružnog računanja jeste priča o zauzimanju teritorije koja će postati Okrug od strane dva brata Folohajda, „sa velikom pratnjom Hobita” i uz „dopuštenje od velikog kralja u Fornostu” (17): od njih kralj zauzvrat traži da „održavaju u dobrom stanju Veliki most, i sve druge mostove i puteve, potpomažu kraljeve glasnike i priznaju njegovo gospodarstvo" (17) - dakle rimsko-britanski imperijalizam i kolonijalizam u minijaturi. Sledeća pažljivo odabrana informacija, već sugerisana napomenom o kraljevom dopuštenju, jeste to čiji su podanici Hobiti: kome se klanjaju, jer je u Tolkinovom svetu klanjanje neupitno. „Ostao je, svakako, prastari običajni odnos prema uzvišenom kralju u Fornostu, ili Norberiju, kako su ga oni zvali, severno od Okruga”. Ali u vreme kada počinje priča - a narator je, potpuno u maniru ranog realističnog romana, vrlo precizan, te znamo da je u pitanju četvrtak, 22. septembar 3001. (ili 1401 prema Okružnom računanju) - „tamo nije bilo nikakvog kralja” (23), čime se već u Prologu nagoveštava povratak istog na kraju trilogije. ${ }^{8}$

I kada se malo bliže fokusira na Okrug, a ne samo na njegovu lokaciju na mapi ili poziciju u istoriji, opet su proizvedene činjenice koje se tiču veličine i vlasti (mada, ne treba zaboraviti, još će i celi pododeljak Pogovora biti posvećen „uređenju Okruga”).

Četrdeset liga se ona protezala od Dalekih visoravni do Brendivjanskog mosta, a pedeset od Severnih baruština do Močvara na jugu. Hobiti su je nazvali Okrug, kao oblast pod vlašću njihovog Namesnika i kraj sa dobro uvedenim poslovima... (18).

Sledeća stavka, koja logično proizilazi iz one istorije koju Tolkin pripoveda, su naravno ratovi - navodi se da Hobiti „ma koje vrste” nisu ratoborni, ali, kao što primer „bitke Zelenih polja, 1147. O. R.” pokazu-

8 Priča - makar onaj deo koji se odnosi na hobite i Prsten - počinje $i$ završava se 22. septembra: Tolkin je toliko precizan u svojoj fantastičnoj istoriografiji da u Dodatku navodi da je Semvajs Gemdži, poslednji nosilac Prstena, poslednji put viden u Okrugu 22. septembra 1482. kada je, nakon smrti svoje voljene supruge „izjahao iz Bagremove ulice [...] otišao u Sive Luke i prešao preko mora” (PK: 370). Priča je prešla pun krug - njen autor je zaista gospodar prstena. 
je, „srčani su kad ih priteraju u tesnac” (19), što će naročito demonstrirati Semvajs Gemdži, Meri i Pipin u svojim odvojenim bitkama.

Hobitima se u Prologu pristupa i sociološki, te se navode neki podaci o njihovom društvu, klasama, porodičnom životu: prvobitno su živeli u rupama u zemlji, kaže narator-istoričar, ali u Bilbovim danima „samo najbogatiji i najsiromašniji Hobiti održavali su taj običaj” (19). Siromaštvo, prihvaćeno i predstavljeno kao činjenica, nije objašnjeno - za razliku od bogatstva, koje se, u prepoznatljivo imperijalističkom maniru, locira u „stranim zemljama” gde samo čeka da ga neko ko dolazi sa Zapada „pokupi” (36). Inače, svoje kuće, mlinove i radionice Hobiti grade iznad zemlje; u kućama živi po nekoliko generacija jer su „svi Hobiti bili skloni klanu” (20).

Ovaj deo, koji daje opšte odlike jednog geografsko-istorijskog prostora i rase/naroda, reprodukujući metodologiju prepoznatljivih naučnih i imperijalističkih disciplina, praćen je mini-traktatom o „travi-za-lulu”. Razmatranje hobitske ljubavi prema duvanu svakako može da se tumači kao komični predah i čak Tolkinovo spajanje „uzvišenog i niskog" u svrhe potencijalne demokratičnosti, ${ }^{9}$ ali isto tako i kao dalje rekreiranje imperijalističke antropologije, uz dodatak istraživačke, imperijalističke botanike:

9 V. Marjorie Burns ‘King and Hobbit: The Exalted and Lowly in Tolkien’s Created Worlds' (u The Lord of the Rings, 1954-2004 : Scholarship in Honor of Richard E. Blackwelder, edited by Wayne G. Hammond, Christina Scull. 2006 Marquette University Press: 139-153). Njena teza je da, uprkos tome što „Tolkinov naglasak ostaje na onima koji su 'visoko' po rangu u svojim društvima/narodima, „Tolkin toliko često, u različitim oblicima i na toliko mnogo nivoa, odigrava sklanjanje onih koji su preambiciozni i koji zloupotrebljavaju moć autoriteta (od Melkora do Sarumana do Gospodara Grada na jezeru) da se ova shema približava sugestiji osude subjektivnog prava” (149). Koliko god ovo zvučalo privlačno, ipak je teško prihvatiti da Povratak kralja, na primer, osuđuje bilo monarhiju bilo apsolutno subjektivno pravo koje pripada vladaru. Ovaj esej je još jedan u nizu onih koji pokušavaju da odbrane Tolkina od opravdanih napada te da njegovoj trilogiji pripišu onu kompleksnost (u smislu ambivalentnosti prema društvenom sistemu koji se rekreira/potvrduje) koja - za razliku od kompleksnosti detalja i podataka - nije tu. Eliminacija onih koji zloupotrebljavaju autoritet nije isto što i eliminacija autoriteta, niti sistema koji ga podržava. 
Danijela Petković: Dž.R.R. Tolkin,fantastika i realizam...

Ima još nešto o Hobitima iz davnine što se mora spomenuti, jedan zapanjujući običaj: oni su kroz lule od ilovače usisavali ili udisali dim gorućih listova izvesne biljke koju su nazivali trava-za-lulu ili list; verovatno neku iz vrsta Nicotiana. Mnogo je tajanstva oko porekla ovog čudnog običaja, ili 'umetnosti', kako su Hobiti više voleli da ga zovu. Sve što se moglo otkriti o tome od davnine sakupio je Merjadok Brendibak (kasnije Starešina Baklenda)... (21).

U delu o „uređenju Okruga” navode se opet podaci o raspodeli i održavanju ekonomske, socijalne i političke moći. Neiznenađujuće za roman koji je „neobično mimetičan” (Rosebury 2003: 15), daju se, najpre, imena „starih vodećih porodica”, od Tukova do Baginsa i Bofinsa (Tuk i Bagins su, ne slučajno, i protagonisti romana); zatim se objašnjava položaj i uloga Namesnika i Okružnih službi, koje se dalje dele na Glasničku službu i Stražu. Stražari su „u praksi bili više poljari nego policajci, zainteresovaniji za zastranjivanje stoke nego sveta” (23). Najveći deo Straže, ipak, odlazi na Graničare, koji su zaposleni da „tabanaju granicama” i da paze da „Tuđinci ma koje vrste, veliki ili mali, ne dodijavaju" (23). Ksenofobija i mržnja prema imigrantima, „tuđincima” pripisane su simpatičnom malom narodu sa kojim čitalac treba da se identifikuje, ili makar saoseća - i didaktičnost i mimetičnost su potpuno jasni.

Nalaženje Prstena je, dalje, detaljno objašnjeno, sa (za zaplet i rasplet važnim) ispoljavanjem „samilosti”, koja Bilba Baginsa sprečava da ubije Goluma, i sa opet preciznom hronologijom i lokacijama. Bilbo se, čitateljka saznaje, vraća u svoj dom koji se nalazi u Bagremovoj ulici, bb., u zapadnoj Četvrtini Okruga, 22. juna 1342. O.R., „i ništa se naročito značajno nije zbilo u Okrugu dok g. Bagins nije počeo pripreme za proslavu svog sto i jedanaestog rođendana (O.R. 1401.)" (27).

Najzad, „Beleška o Zapisima Okruga” informiše čitaoca o lokacijama, naslednicima i potencijalnim datumima proizvođenja Bilbove Crvene knjige koja služi kao istorijski zapis - iako se insistira na nepouzdanosti i prepisivanju knjige sa svim potencijalnim propustima i greškama, upravo je taj proces prepisivanja, pre nego činjenice, ono što garantuje realističnost. 
Originalna Crvena knjiga nije sačuvana, ali mnoge kopije su bile načinjene, naročito od prve sveske, za upotrebu potomaka dece Starešine Semvajsa. Najznačajnija kopija, međutim, ima drugačiju istoriju. Ona je čuvana u Velikim Smialima, ali je napisana u Gondoru, verovatno na zahtev prapraunuka Peregrinovog, i završena u O.R. 1592 (Č.R. 172). Njen pisar s juga dodao je ovu belešku: 'Findedžil, Kraljev Pisac, dovrši ovaj rad u IV 172. To je tačna kopija u svim pojedinostima Knjige Namesnika u Minas Tiritu. Ta knjiga beše kopija Crvene knjige Perjanata, načinjena na zahtev kralja Elesara, a beše mu doneta od strane namesnika Peregrina kada se ovaj povukao u Gondor, u IV 64’. (28)

Istoriju bukvalno pišu moćni (učeni i bogati), na zahtev moćnih; ona je, dalje, generacijama, u rukama starešina i namesnika: sve je rečeno o ideološkim pretpostavkama zvaničnih i „stvarnih” istorija. Tolkin, budući da je i sam, ideološki, „kraljev pisac”, ne problematizuje nego normalizuje ovu praksu.

\section{TOLKINOVA PROBLEMATIČNA FANTASTIKA}

Implikacije ovakvog Prologa su višestruke, za sam roman, u pogledu tema, strukture i ideologije; ali i za Tolkinovu fantastiku, realističnost, autorsku moć i najzad didaktiku. Da krenemo redom.

Prolog daje realističan, prvenstveno istorijski okvir, ali na svega nekoliko strana uvodi sve ono što će biti razrađivano u nastavku trilogije: detaljna geografija, Hobit sa prstenom, Golum, bitke, povratak kralja, samilost koja će odigrati važnu ulogu u „Ratu za Prsten”, i, najzad, proizvođenje tekstova o svemu ovome. Sve teze i svi narativni postupci Gospodara prstenova prisutni su, dakle, već u Prologu, od obilnih geografskih podataka do potpune demonizacije neprijatelja. Već u Prologu, naime, Golum je određen svojom vezanošću za prsten, odnosno moć koja mu ne pripada, i eksplicitno je prikazan kao biće na nižem evolutivnom, kulturnom i (samim tim) moralnom razvoju. Posebno je zanimljivo da se ovo složeno pozicioniranje, kao i u dečjim knjigama K. S. Luisa, izvodi preko kulinarstva: naime, za razliku od ,junaka”, Golum ne kuva nego jede živu hranu, dok se Semvajs 
Gemdži drži svojih tiganja sve do kraja. Dehumanizacija neprijatelja, nagoveštena tretmanom Goluma u Prologu je u nastavku ove ratne istorije obavljena u skladu sa Tolkinovim istančanim osećanjem za rasnu i klasnu hijerarhiju (a ta istančanost već mnogo govori): dok je Golum tek shizofrena zverčica koja guta sirovu ribu, dotle su Orci već zastrašujuća čudovišta, Šeloba je ogroman pauk koji isisava žrtve, a Sauron je sveden na plamteće oko, bez ikakve fizičke forme koja bi makar podsećala na ljudsku/vilovnjačku.

Kada je reč o geografiji, mapa i lociranje Okruga ili praćenje seoba Hobita u Prologu nisu ništa u poređenju sa bogatstvom i preciznošću detalja koji se umnožavaju i gomilaju kako priča „raste sa pričanjem”. Družina prstena, posebno, prati kretanje najpre grupe Hobita a zatim i predstavnika „Slobodnih naroda” gotovo korak po korak. Kao što je moguće pratiti uznemirenu Mol Flanders po Londonu na osnovu naziva ulica koje ona navodi (DeFoE 2006: 181), tako je moguće pratiti svaki delić puta koji Hobiti prelaze od Okruga do Rivendala, od Rivendala do Morije, Rohana, Gondora i najzad, Mordora, sa 655 navedenih tačaka između..$^{10}$ Neki od ovih toponima su imenovani na dva ili tri jezika, i ukotvljeni su ne samo u prostor, mapama, nego i u vreme istorijskim podacima/anegdotama. Ovo je, na primer, delić puta ka Briju: „Posle nekog vremena prešli su Vodu, zapadno od Hobitona, preko uzanog daščanog mosta. Tok na tom mestu nije bio više od vijugave crne trake, oivičen nadvijenim drvećem jove. Milju-dve dalje na jugu užurbano su prešli onaj veliki put kod Brendivajnskog mosta; tako su se našli u Tuklendu, i, skrenuvši na jugoistok, pošli prema oblasti Zelenih brda" (DP: 85).

Čak su i dijalozi - razgovori između prijatelja - prepuni proverljivih geografskih podataka i detalja vezanih za hronologiju. Ovako, na primer, govori Gandalf:

Krajem juna boravio sam u Okrugu, ali neka senka uznemirenja bila mi je u mislima, te sam odjahao do južnih granica te male zemlje; jer predosećao sam neku opasnost, još skrivenu od mene ali u primicanju. Tu su me stigle

${ }^{10}$ Navedeno prema „Indeksu mesta” iz engleskog izdanja Gospodara prstenova (TOLKIEN 1995: 1125-133). 
poruke koje su mi kazivale o ratu i porazu u Gondoru, i kada sam čuo o Crnoj Senci jeza mi je obuzela srce. Ali nisam našao ništa do nekoliko izbeglica sa Juga; izgledalo je da ih pritiska neki strah o kome neće da govore. Krenuo sam tada na istok i sever, i putovao Zelenputem, i, nedaleko od Brija, naišao sam na jednog putnika kako sedi na nasipu pokraj druma, a konj je pasao pored njega. Bio je to Radagast Mrki, koji je u svoje vreme živeo u Rozgobelu, blizu granica Mrke šume. (DP: 274)

Ovako govori Aragorn:

Sada smo došli do reke Horvel, koju Vilovnjaci zovu Mitejtel. Ona teče iz Etenskih visoravni, trolovskih oblasti severno od Rivendala, i spaja se sa Glasnom Vodom dole na jugu. Neki je zovu reka Sivotok, posle toga. To biva velika voda pre nego što pronađe more. Nema puta preko nje niže njenih izvora u Etenskim visoravnima, osim Poslednjeg mosta kojim put prelazi. (DP: 217)

U dubinama Morije, takođe, podaci, koje Gandalf navodi odmah nakon pozdrava „dobro jutro”, su sledeći: „Mi smo visoko gore na istočnom boku Morije. Pre nego što današnji dan prođe trebalo bi da nađemo Velike kapije, i vidimo vodu Jezera Ogledala gde leži u Dimril-Dolu pred nama" (Dp: 339).

Sedamsto podjednako detaljnih strana kasnije, lokacije su još preciznije, mapira se ne samo oblast nego grad (ovde Minas Tirit) njegove ulice, i konkretne zgrade: „Sad konačno prođoše u visoke krugove Grada, i u svetlosti jutra odoše putem prema Kućama isceljenja; [...] One su stajale nedaleko od Kapije Citadele, u šestom krugu, blizu Južnoga zida, a oko njih je bila bašta, i jedna livada sa drvećem; jedino takvo mesto u Gradu" (Pk: 125). I tako dalje, i tako dalje, na preko hiljadu strana. Tolkin, čini se, decenijama unapred pravi verbalni ekvivalent Google Maps, i to epsko-biblijskim jezikom. Njegova istorija bi trebalo da se čita uz mape i hronologiju koji su svi navedeni u Dodacima - svaki korak i svaki datum (godina, mesec, dan u nedelji) su proverljivi i uklapaju se u celinu.

Brajan Rouzberi (Brian Rosebury) navodi da je „Srednji svet, a ne bilo koji od likova, pravi junak Gospodara prstenova” (RoseBURY 2003: 34), ali, kao Tolkinov apologeta, nastavlja insistiranjem da „emotivna snaga [trilogije] barem podjednako leži u fascinaciji i lepoti Srednjeg 
sveta, koliko i u uzbudljivom zapletu” (34). Za razliku od „emotivne snage" koja je u najboljem slučaju diskutabilna, realističnost i mimetičnost Tolkinovog fantastičnog sveta su ne samo neporecivi nego i upadljivi. Pri tom ne mislim samo na ono što je očigledno iz mapa - da je Srednji svet oblikovan po uzoru na Evropu ${ }^{11}$ - već na same mape, na detaljno opisane prostore koji se prelaze korak po korak, iz dana u dan, što je sve precizno zabeleženo (kako bi inače ova priča „rasla sa pričanjem”?). Mada u predgovoru tvrdi da je hteo „neophodnu istorijsku pozadinu" za svoje vilovnjačke jezike (i svoju ratnu fantaziju), jasno je da Tolkin stvara i geografiju. Ono, pak, što je otkrio kreirajući ovakav (hiper)realistični okvir jeste upravo sopstveno nepoverenje u imaginaciju i fantastiku, koje je projektovao na čitaoce.

Tolkinova fantastika, njegov Srednji svet sa svojim rasama, istorijama, genealogijama i analima kraljeva, sukobima, kalendarima, jezicima i predanjima, nesumnjivo je mimetička. Ali Tolkin ne reprodukuje Evropu, nego kreiranje iste kartografijom; ne stvara nove narode nego pravi antropologiju fantastičnih bića (koja pozajmljuje iz bajki i skandinavsko-germansko-engleskih mitologija); pišući istoriju Rata za Prsten i sve istorije kraljeva i sukoba, on ih oblikuje prema evropskim, reprodukujući njihove teme i diskurs. Čak su i prepoznatljivo fantastični elementi proizašli iz stvarne politike i odnosa moći - neprijatelj je demonizovan i dehumanizovan do tačke kada mu se ukida telo; „dobri” su prepoznatljivo beli Anglosaksonci, kulturno i moralno napredni narodi koji pišu istorije, pevaju pesme i ispredaju priče na jednu te istu temu (junački podvizi); koji jedu kuvanu hranu, puše duvan i piju pivo. (Takođe su i, neki od njih, muževni na onaj ograničeni način pop kulturnog konstruisanja srednjovekovnih vitezova.) Tolkin se u Predgovoru drugom izdanju Gospodara prstenova elokventno odredio prema alegoriji, koju je „prezirao”: Gospodar prstenova je, kako on insistira, istorija a nikako alegorija. Ali ova istorija je prepoznatljivo bela, engleska - kao i kod Luisa, „tuđinci' izvan granica prave probleme i treba ih eliminisati; neprijatelji su sa divljeg juga, imaju

11 Tolkin i sam priznaje: „scena moje priče je ova zemlja, ova u kojoj živimo, ali je istorijski period izmišljen" (citirano u RosebuRY 2003: 14-15). 
kose oči i tamnu kožu. To možda nije alegorija, ali svakako nije ni nezavisna, maštovita kreacija. A to što je Tolkin verovao da jedino takav okvir može da „začara” čitaoca (onog trenutka kada čitalac posumnja u nešto, setimo se, „magija ili umetnost su omanuli”), kaže još nešto i o tom implicitnom čitaocu i o Tolkinovom naslanjanju na naučne discipline. Ne radi se, naime, o tome da će čitalac biti začaran koliko već istreniran, obaveznim školovanjem, da istoriju (onu koja se fokusira na ratove i kraljeve) i geografske podatke prihvata kao garant „stvarnosti”.

Takođe, toponimi ukorenjeni u prostor (mapama) i vreme (anegdotama iz prošlosti koje se za njih vezuju) i, naročito, hronologija, precizni su do tačke nenamernog auto-parodiranja. U Dodatku se, između ostalog, nalazi i sledeći podatak:

U Numenoru računanje je počinjalo od godine 1 D. R. Manjak prouzrokovan odbijanjem 1 dana od poslednje godine veka nije bivao izglađen do poslednje godine milenijuma, ostavljajući tako jedan hiljadugodišnji manjak od 4 sata, 46 minuta, 40 sekundi. Ova dopuna načinjena je u Numenoru u D. R. 1000., 2000., 3000. Posle Pada u 3319 D. R. ovaj sistem održavali su izgnanici, ali on je bio veoma poremećen otpočinjanjem trećeg razdoblja novom numeracijom: 3442 D.R. postala je 1. godina T.R. Time što je godina 4. T.R. učinjena prestupnom, umesto 5. T.R. (3444. D.R.), jedna je kraća godina, od samo 365 dana, bila umetnuta, izazivajući manjak od 5 časova, 48 minuta, 46 sekundi. Milenijalne dopune bile su načinjene sa 441 godinom zakašnjenja: u 1000. T.R. (4441 D.R.) i 2000. (D.R. 5441.). Da se umanje greške ovako prouzrokovane, i nagomilavanje hiljadugodišnjih deficita, Mardil Domostrojitelj izdao je jedan preinačen kalendar koji je imao da stupi na snagu u 2060. T.R. posle specijalnih dodavanja od 2 dana godini 2059. (5500 D.R.) koja je navršila 5 1⁄2 milenijuma od početka numenorejskog sistema. Ali ovo je još ostavilo oko 8 časova deficita. (Pк: 378-9)

Hronološka preciznost, u rukama Emili Bronte (Emily Brontë) na primer, obezbeđuje realističan okvir priči koja prevazilazi realizam (i u tome je još više realistična); ova vrsta preciznosti koju Tolkin demonstrira (a reč je o samo jednom paragrafu u Dodatku na stotinu strana, u sitnom fontu) je toliko detaljna da je, nenamerno, samoporažavajuća. Da je u pitanju neki drugi pisac, možda bi moglo da se protumači kao nonsens, kao duhovito poigravanje sa konvencijama realizma i nau- 
ke, ali pošto je Tolkin dobro poznat po svojoj ljubavi prema istoriji, teško da je tako. Pre će biti da je u pitanju ispad - na epskom nivou - sličan Defoovom (Daniel Defoe) navođenju ulica u epizodi u kojoj Mol Flanders razmatra ubijanje devojčice koju je opljačkala. Duboko uznemirena, Mol ipak ostavlja dete u životu, i zatim kreće svojoj kući, kroz precizno redom navedene ulice, sa svim skretanjima, koje je moguće pratiti na mapi Londona. Ulice koje postoje i na mapi i u nekoj objektivnoj stvarnosti treba da daju kredibilitet Mol Flanders koja je proizvod Danijela Defoa. Ali zašto bi se (i kako bi se) stvarna žena sećala svake uličice u koju je zašla, rastresena (tako bar tvrdi) nakon jednog zločina i kontempliranja još jednog, neuporedivo goreg? A treba uzeti u obzir i da Mol Flanders kao naratorka priča o svojoj prošlosti, o događaju koji se desio mnogo godina ranije. Defo se, jasno je, previše trudi da bude realističan i , istinit”: njegov trud otkriva nervozu autora novog, u tom trenutku (1722) ne mnogo cenjenog žanra (ne mnogo cenjene klase) koji sebi pribavlja kredibilitet pozivanjem na tzv. stvarni svet, u kome postoje Njugejt, deca sa zlatnim lančićima i ulice sa nazivima. Tolkin se, sa druge strane, trudi u tolikoj meri da otkriva potpunu artificijelnost ranih realističnih konvencija kakvo je „precizno vreme”. Ali njegov trud nije proizvod nervoze, nego očiglednog uživanja u sopstvenoj stvaralačkoj moći: Mardil Domostrojitelj je možda napravio preinačeni kalendar i svojom voljom uredio vremenski tok; Tolkin je stvorio i Mardila, i sve kalendare, i manjak, i višak, i sve (mnogo toga) ostalo.

Ova moć autora (naratora, istoričara, geografa-kartografa, hroničara, antropologa, filologa koji sakuplja „narodno stvaralaštvo”, pesnika i mitomana ${ }^{12}$ ) dalje se podcrtava jezikom koji, uprkos protestima

${ }^{12}$ A upadljivo je da su u pitanju preokupacije i discipline iz 19. veka, od imperijalističke antropologije do filologije i sakupljanja narodnog stvaralaštva braće Grim, na primer. Iz malo drugačije perspektive - njen fokus je na gotici - Su Zlosnik (Sue Zlosnik) takode ukazuje na vezu Gospodara prstenova sa devetnaestim vekom, čitajući ga kao tekst koji „mada smešten u mitsku prošlost, jeste preokupiran strahovima dvadesetog veka koga još opsedaju devetnaestovekovni nemiri" (v. 'Gothic Echoes' u Bloom 2008: 118). Što se tiče Tolkina kao mitomana, v. Jane 
brojnih Tolkinovih apologeta, ${ }^{13}$ zaista zvuči biblijski (ili pseudobiblijski, prema Haroldu Blumu; Bloom 2008: vii), naročito kako priča odmiče, i pozajmljivanjem likova iz nordijske, germanske i engleske mitologije, bajki i popularne kulture.

\section{ZAKLJUČAK}

Na formalnom planu, koji je uvek i ideološki, Gospodar prstenova kombinuje romansu i istoriju, mitologiju i antropologiju, pop kulturu i kartografiju, u jasnoj nameri da se (implicitno) odrasli čitalac poduči ispravnom rodnom i klasnom, ali i moralnom ponašanju. U kontekstu „istorije Rata za Prsten”, ovo ispravno ponašanje podrazumeva borbu protiv potpuno demonizovanog neprijatelja, bespogovorno prihvatanje autoriteta više rase/klase, i pokazivanje samilosti prema uniženima. (Ili, pružanje prilike uniženima da budu eksploatisani i nazivanje toga milošću, što naročito dobro ilustruje postupanje sa Golumom u Dve Kule, v. Dк: 233.) Tolkinovo posezanje za starim i novim (obrazovnim) autoritetima - najupadljivije imperijalističkim naučnim disciplinama - ukazuje na želju da se vrednosti i obrasci iz njegove „duge priče” internalizuju. Sa druge strane, reprodukovanje naučnih metodologija prilikom pod-kreiranja fantastičnog sveta nužno problematizuje odnos fantastike (preciznije, velikih zahteva koje Tolkin postavlja pred istu u predavanju „O bajkama”) i realizma (ne samo u književnosti nego u smislu proizvođenja dogovorne, navodno objektivne, stvarnosti). Rezultat je „neobično mimetična” istorija fantastičnog sveta i fantastičnih bića, koja je tek minimalno izmeštena u odnosu na političke i vojne igre moći (poznate i kao ratovi) iz tzv. stvarnog sveta. (Dakle, ne „neobično” mimetična nego samo mimetična.) Tolkinovo naslanjanje na metodologiju i diskurs prepoznatljivih

Chance, Tolkien's Art: A Mythologyfor England (The University Press of Kentucky, 2001).

${ }^{13}$ Ros Smit (Ross Smith), Stiv Voker (Steve Walker), Tom Šipi, Džejn Čens (Jane Chance) i Ursula Legvin (Ursula K. Le Guin). 
naučnih disciplina (i školskih predmeta) sa jedne strane, i prepoznatljivih figura iz moćnih mitologija, bajki, i popularne kulture sa druge, naučnim, a onda i biblijsko-epskim jezikom, mnogo je manje impresivno i ubedljivo kao primer stvaralačke imaginacije. Cini se da ovakvi narativni izbori pre ukazuju na želju za autoritetom iz svih (ma kako naizgled kontradiktornih) izvora.

\section{IZVORI I CITIRANA LITERATURA}

Brontë, Emily. Wuthering Heights. London: Penguin Books, 1994.

Burns, Marjorie. "King and Hobbit: The Exalted and Lowly in Tolkien's Created Worlds". Wayne G. Hammond and Christina Scull(eds.). The Lord of the Rings, 1954-2004: Scholarship in Honor of Richard E. Blackwelder. Marquette University Press, 2006, 139-153.

CarTer, Angela. The Bloody Chamber and Other Stories. New York: Penguin Group, 1979.

Chance, Jane. Tolkien's Art: A Mythology for England. Lexington: The University Press of Kentucky, 2001.

Mieville, China. "Marxism and Fantasy: Introduction". David Sandner (ed.). Fantastic Literature: A Critical Reader. Westport, CT and London: Praeger Publishers, 2004, 334-345.

Connolly, John. The Book of Lost Things. London: Hodder and Stoughton.

Defoe, Daniel. Moll Flanders. San Diego: Icon Classics, 2006.

Hume, Kathryn. Fantasy and Mimesis: Responses to Reality in Western Literature.

New York and London: Methuen, 1984.

Luis, K. S. Letopisi Narnije, prev. Zoran Jakšić. Beograd: Laguna, 2005.

Mathews, Richard. Fantasy: The Liberation of Imagination. New York and London: Routledge, 2002.

Rosebury, Brian. Tolkien - A Cultural Phenomenon. Basingstoke: Palgrave MacMillan, 2003.

Salo, David. A Gateway to Sindarin: A Grammar of an Elvish Language from J. R. R. Tolkiens's Lord of the Rings. Salt Lake City: University of Utah Press, 2004.

Scull, Christina. "What did he know and when did he know it?" Wayne G. Hammond and Christina Scull (eds.). The Lord of the Rings, 1954-2004: 
Scholarship in Honor of Richard E. Blackwelder. Milwaukee: Marquette University Press, 2006, 101-113.

ShIPPEY, Tom. Roots and Branches: Selected Papers on Tolkien. Zollikofen, Switzerland: Walking Tree Publishers, 2007.

Todorov, Tzvetan. The Fantastic: A Structural Approach to a Literary Genre.

New York: Cornell University Press, 1975.

Tolkien, J. R. R. "On Fairy-Stories". http://brainstorm-services.com/wcu2004/fairystories-tolkien.pdf, pristupljeno 20.septembra $201 \%$.

Tolkien, J. R. R. The Lord of the Rings. London: HarperCollins, 1995.

Tolkin, Dž. R. R. Družina Prstena, prev. Zoran Stanojević. Novi Sad i Beograd: Stylos Art, 2012.

Tolkin, Dž. R. R. Dve kule, prev. Zoran Stanojević. Novi Sad i Beograd: Stylos Art, 2012.

Tolkin, Dž. R. R. Povratak kralja, prev. Zoran Stanojević. Novi Sad i Beograd: Stylos Art, 2012.

ZIPES, Jack. Breaking the Magic Spell: Radical Theories of Folk and Fairy Tales. Lexington: University Press of Kentucky, 2002.

Zlosnik, Sue. "Gothic Echoes". Harold Bloom (ed.). Bloom's Modern Critical Interpretations - J. R. R Tolkien's Lord of the Rings. New York: Infobase Publishing, 2008, 117-129.

Danijela Petković

\section{J. R. R. TOLKIEN, FANTASY AND REALISM: "ON FAIRY-STORIES" AND THE LORD OF THE RINGS}

\section{Summary}

The paper examines J. R. R. Tolkien's celebrated trilogy, The Lord of the Rings, first in the context of Tolkien's 1939 lecture 'On Fairy-Stories'. The aim of the paper is to point to to the problematic nature of both fantasy and realism as exemplified by the trilogy. While Tolkien, in his lecture, insists on the possibility of 'recovery, escape and consolation' provided by fantasy, in The Lord of the Rings he appropriates and reproduces specific scientific methodologies in order to create his fantastic universe. Such narrative choices and ideological preferences necessarilly problematize the relationship between fantasy and realism, as well as the relationship between 
imagination and reality, resulting in a mimetic history which is quite close to the real world political and military power games.

Keywords: fantasy; J. R. R. Tolkien; mimesis; "On Fairy-Stories"; realism; The Lord of the Rings.

Univerzitet u Nišu

Filozofski fakultet

danijela.petkovic@filfak.ni.ac.rs 